\title{
Stop Think: Asthma and Dysfunctional breathing
}

\section{Mike Thomas}

\section{Commentary}

Most clinicians will be familiar with acute hyperventilation, presenting as acute severe breathlessness and panic. There is, however, growing evidence that other less acute but more insidious functional breathing disorders may affect patients in various ways and cause significant symptoms and impairment of quality of life. ${ }^{1}$ Symptoms associated with chronic or recurrent changes in breathing patterns include breathlessness, chest tightness, chest pain, dizziness and anxiety. As the symptoms are not specific, breathing disorders can masquerade as or complicate other conditions, including asthma. ${ }^{2,3}$

There have been reports from hospital based respiratory clinics that patients of all ages referred from the community with both unexplained or disproportionate symptoms or with 'poorly controlled asthma' in fact had functional breathing disorders causing a significant part of their symptoms. ${ }^{4-6}$ The breathing pattern often includes overbreathing, resulting in hypocapnia, although this may not be conspicuous without careful observation, and often includes irregularity and unsteadiness or respiratory effort, predominant use of chest and accessory muscles of respiration rather than the diaphragm in quiet respiration and frequent sighing. ${ }^{7}$ Functional breathing disorders are reported to be more common in patients with higher anxiety levels and with recent significant life events. ${ }^{8}$

We have recently reported a high prevalence of typical symptom patterns of dysfunctional breathing in adult asthmatic patients treated in the community ${ }^{9}$ with $1 / 3$ of women and 1/5 of men possibly affected, and shown that many of these patients can be helped by a short course of physiotherapist-administered breathing retraining. ${ }^{10}$

How can this syndrome be recognised in general practice? Unfortunately there is no 'gold-standard' diagnostic test to confirm the diagnosis, which can be difficult to make. The symptoms are non-specific, and it is important not to miss problems such as undertreated asthma or pulmonary emboli. Awareness of the characteristic symptom pattern (which can be helped by using validated symptom questionnaire instruments such as the Nijmegen Questionnaire ${ }^{11}$ ) can be a pointer, particularly in patients not responding to usual treatment or with symptoms that outweigh objective clinical findings. Patients' symptoms may be unusual - for instance they may report difficult in getting air in, i.e. in inspiration, rather than the expiratory problems characteristic of asthma, or may report sudden and unpredictable 'attacks' in relation to stressful situations. Capnography or blood gas analysis can confirm overbreathing, but are not generally available in general practice. Oximetry will show normal oxygen

\section{Case Study}

Carol is 28 years old and was diagnosed as having asthma in her early teens, on the basis of episodic breathlessness and wheeze associated with viral illnesses, exercise and with personal stress. Wheezing and a variable peak flow reading (varying between $80 \%$ and $110 \%$ of predicted values) are noted in her old medical records. Generally her asthma has been mild in the past, controlled by PRN salbutamol and intermittently by inhaled beclomethasone, not used for several years.

She is currently engaged to be married, about to move into a new home with her fiancé, working full time in a stressful job.

She has attended the surgery 6 times in the last 3 months complaining that her asthma has been bad. Her short-acting bronchodilator usage has averaged 2 canisters a months. Four months ago inhaled steroids were re-introduced, and 2 months ago a long-acting bronchodilator was added. Last month she remained very symptomatic, complaining of bad asthma episodes at work and at home, and a leukotriene antagonist was added. Physical examination at the surgery has not revealed wheezing and her peak flow has been between $85 \%$ and $95 \%$ of predicted on all occasions. Her fiancé has come with her and reported how bad her asthma attacks can be, and how she 'just can't get air in' during them. On one occasion she attended A\&E, where the peak flow was said to be 'unrecordable' on arrival but rose to $90 \%$ predicted after nebulised salbutamol and a period of rest and observation.

She admits to poor sleep and reports feeling very anxious about her health, her uncontrolled symptoms and life in general.

Detailed questioning reveals the presence of symptoms of chest pain, chest tightness, paraesthesiae and light-headedness during attacks, and persistent fatigue and myalgia. She also admits to high stress levels, and is worried that she will stop breathing during the attacks. She finds most difficulty with inspiration rather than expiration, and between attacks does not feel tight or wheezy but feels tired. The medication she has been prescribed has not seemed to help, other than the salbutamol, which she admits she over-uses and relies upon.

Careful examination reveals no cyanosis or wheeze and her peak flow is $95 \%$ of predicted. Moderate tachypnoea and the use of accessory muscles of respiration are observed. When asked to hold her breath in inspiration, she can only manage to do so for 7 seconds. When asked to voluntarily hyperventilate, after 30 seconds she became distressed with panicky feelings, breathlessness and chest pain, which resolved with slow steady breathing.

A presumptive diagnosis of dysfunctional breathing complicating asthma was made and she was referred to a respiratory physiotherapist for breathing retraining. 2 months later her symptoms were greatly improved and she reported feeling much more in control of her asthma and her breathing, having more energy and being more relaxed. The leukotriene antagonist and later the long-acting bronchodilator were stopped without loss of control, and her short-acting bronchodilator use was greatly reduced.

saturation in dysfunctional breathing and hyperventilation, and low values may be useful in suggesting alternative diagnoses, such as for example pulmonary thromboembolism. Demonstration of a short breath-holding time and the production of symptoms by a brief (up to 2 minute) period of voluntary hyperventilation can be useful pointers. 
When in doubt, however, referral to an appropriately trained respiratory physiotherapist, who can educate, reassure and teach diaphragmatic breathing exercises, may make an important difference in a patient's lifeand may allow reduction in ineffective medication. The diagnosis can only be confirmed by a resolution of symptoms when the breathing pattern is improved.

\section{Mike Thomas}

Principal in General

Practice, GPIAG Research

Fellow, University of

Aberdeen

Correspondence to:

The Surgery

Minchinhampton

Stroud

Gloucester GL6 9JF

Tel: $+44(0) 1453883793$

Email:

drmthomas@oakridge.sol.co.uk

Prim Care Resp J 2003;

12(1):25-26

\section{References}

1. Gardner WN. The pathophysiology of hyperventilation disorders. Chest 1996;109:516-34.

2. Ringsberg KC,.Akerlind I. Presence of hyperventilation in patients with asthma-like symptoms but negative asthma test responses: Provovation with voluntary hyperventilation and mental stress. J Allergy Clin Immunol 1998;103:601-8. 3. Hammo A,.Weinburger MM. Exercise induced hyperventilation: a pseuedoasthma syndrome. Ann Allergy Asthma Immunol 1999;82:574-8.

4. McClean AN, Howells J, Chaudri G, Boyd G. Use Of The Nijmegen Hyperventilation Questionnaire and Hyperventilation Provocation Test In A Hospital Asthma Clinic. Am J Respir Crit Care Med 1999:159:A652.

\section{Care Respiratory Journa:}

5. Nigemann B. Funcrional symptoms confused with allergic disorders in childen and adolescents. Paed Allergy Immunol 2002:13: 312-318.

6. Goldberg BJ,.Kaplan MS. Non-asthmatic respiratory sympomatology. Curr Opin Pulm Med 2000;6:26-30.

7. Han JN, Stegen K, Simkens K, Caubergs M, Schepers R, .Van den Bergh O. Unsteadiness of breathing in patients with hyperventilation syndrome and anxiety disorders. Eur Respir J 1997;10:167-76. 8. Howell JBL. The hyperventilation syndrome: a syndrome under threat? Thorax 1997;52(suppl):S30S34.

9. Thomas M, McKinley RK, Freeman E, et al. Prevalence of dysfunctional breathing in patients treated for asthma in Primary Care- a cross sectional survey. BMJ 2001;322:1098-100.

10. Thomas M, McKinley RK, Freeman E, Foy C, Prodger P, Price D. Breathing retraining for dysfunctional breathing in asthma- a randomised controlled trial. Thorax 2003; in press.

11. van Dixhoorn J,.Duivenvoorden HJ. Efficacy of Nijmegen questionnaire in recognition of the hyperventilation syndrome. J Psycosom Res 1985;29:199-206. 